\title{
Collaboration-Based BIM Model Development Management System for General Contractors in Infrastructure Projects
}

\author{
Yu-Cheng Lin $(\mathbb{D}$, Nan-Hai Lo, Hsin-Tzu Hu, and Ya-Ting Hsu \\ Department of Civil Engineering, National Taipei University of Technology, No. 1, Sec. 3, Zhongxiao E. Rd., Taipei, Taiwan \\ Correspondence should be addressed to Yu-Cheng Lin; yclinntut@gmail.com
}

Received 20 August 2020; Revised 10 October 2020; Accepted 14 October 2020; Published 28 October 2020

Academic Editor: Salvatore Antonio Biancardo

Copyright ( $) 2020 \mathrm{Yu}$-Cheng Lin et al. This is an open access article distributed under the Creative Commons Attribution License, which permits unrestricted use, distribution, and reproduction in any medium, provided the original work is properly cited.

\begin{abstract}
For mass rapid transit (MRT) projects, the characteristics of MRT engineering include large scopes, long durations, complex interfaces, significant requirements for management, and complicated coordination and cooperation. Owing to the complexity of these projects, the use of building information modeling (BIM) technology will be necessary and helpful to improve construction management. The increasing application of BIM in the architecture, engineering, and construction (AEC) industries has strengthened the need for effective construction management for general contractors (GC) for BIM implementation during the construction phase. Collaboration-based BIM model development for GCs typically involves relevant participants from different fields during the construction phase of MRT projects. However, collaboration-based BIM model development tasks often create numerous practical problems (e.g., reworks and errors regarding BIM model development). As the BIM manager and engineers for the general contractor who handle BIM model development are located in different departments and different office locations in MRT construction projects, a centralized platform is needed to share the latest real-time BIM model developments for related participants. Effective collaboration-based BIM model development management (CBMDM) is therefore essential for GCs to obtain accurate BIM models before the implementation of BIM-related applications. While the latest information for collaboration-based BIM model development should be updated and tracked effectively for CBMDM for related participants during the development process, in practice, GCs lack systematic approaches and information management platforms for use in CBMDM tasks. Thus, this study proposes a novel approach and develops an information system to manage and track all CBMDM tasks for GCs during the BIM development process. The purpose of this study is to develop a CBMDM system to improve the efficiency of sharing and tracking information for CBMDM activities. The research scope of this study is to propose an approach and system for CBMDM work in large-scale construction and infrastructure projects. The CBMDM system assists users by providing workflow management of CBMDM tasks for BIM engineers and managers so users can manage all BIM model development tasks effectively. The proposed system can also be utilized for other types of large-scale construction projects for CBMDM tasks. Furthermore, to understand its effectiveness, the proposed CBMDM system is applied to a case study of an MRT project in Taiwan. Finally, the major practical advantages, disadvantages, and limitations of the system are identified for infrastructure projects.
\end{abstract}

\section{Introduction}

The characteristics of mass rapid transit (MRT) engineering include large scopes, long durations, complex interfaces, significant requirements for management, and complicated coordination and cooperation. Owing to the complexity of these projects, combining the project with building information modeling (BIM) technology will be necessary and helpful to improve construction management. BIM is a parametric 3D computer-aided design (CAD) technology that has been applied in the architecture, engineering, and construction (AEC) industries [1]. General contractors (GC) should consider using these accurate as-built BIM models before using various BIM-related applications. During the construction phase of an infrastructure project, general contractors need to handle the as-built BIM model development (abbreviated to BIM model development in this paper) for BIM implementation. However, BIM model development usually causes various time-consuming problems. Therefore, GCs in Taiwan tend to adopt a 
collaboration-based BIM model development process to shorten the duration of the model's development process during the construction phase of an MRT project.

Particularly in MRT construction projects, collaborationbased BIM model development management (CBMDM) involves participants from different domains during the development processes. In general, email or oral communication is the most practical method for BIM managers and engineers using CBMDM to communicate and respond to changes in information. As the BIM manager and BIM engineers who handle BIM model developments are located in different departments and different office locations for general contractors in MRT construction projects, a centralized platform is needed to share the latest real-time BIM model developments for the related participants. While many studies in academic and practical literature discuss BIM-related collaboration management, few studies have focused on the management of collaboration-based BIM model development for GCs. Furthermore, an issue for the practical implementation of CBMDM is that no appropriate system exists to help BIM engineers and managers track and manage the latest information and statuses of CBMDM tasks for GCs. This makes it difficult for BIM engineers and managers to effectively manage and track all updated information and results for CBMDM tasks using email or general information systems. In CBMDM, without an effective approach and suitable system, poorly coordinated and controlled tasks will cause practical problems, such as coordination difficulties of CBMDM tasks and BIM model mistakes.

During the implementation of CBMDM, the related status, results, and details of CBMDM tasks must be updated and tracked effectively. However, currently, the updates are generally not transmitted or tracked effectively among BIM engineers and managers. Moreover, BIM engineers frequently execute their tasks without reporting the latest information and status for CBMDM to other BIM engineers. To enable BIM managers and engineers to track and manage CBMDM tasks, this study aims to facilitate a tracking and management system for GCs for CBMDM. To promote the effective implementation of CBMDM, this study also develops a CBMDM system for BIM engineers and managers to improve the sharing and tracking of information, as well as to enhance the results of CBMDM tasks. The research scope of this study is to propose an approach and system for CBMDM work in large-scale construction and infrastructure projects. The proposed CBMDM system is not only suitable for MRT projects but also can be utilized for other types of large-scale construction projects for CBMDM. BIM engineers and managers can use the CBMDM system to obtain an overview of previous and current information and track the results of CBMDM tasks for a given project. The latest information and results of the CBMDM tasks can be analyzed and shared among all BIM engineers and managers involved in advanced decision-making.

\section{Literature Review}

In the 1980s and early days of CAD, researchers have conceptually described the concepts of BIM [2]. However, just in recent years, its importance of design and construction integration increased. From the early 2000s, the construction sector and academic studies related to construction started to understand the value of BIM [3]. From the initial days to the present, BIM revolutionary technology and processes quickly transformed the way buildings are comprehended, planned, constructed, and operated [4]. Over the years, BIM has advanced and the modern-day BIM has surpassed the concepts discussed a few decades back [5].

BIM is a digital representation of the physical and functional characteristics of a facility that allows the digital construction of accurate virtual models $[6,7]$. To support the design, procurement, fabrication, and construction activities required to understand the building system, BIM models provide precise geometry and relevant data [8]. BIM can enhance the manager's comprehension of information through the employment of spatial data visually presented in $3 \mathrm{D}$ models [9]. A collaborative relationship is essential to the process of project delivery in sustainable building construction. For both academics and practitioners, the development of collaborative interaction across professions becomes a fundamental issue [10].

BIM adoption for sustainable building projects incorporates a considerable impact and influence on sustainable collaboration. BIM can contribute to FM as a source of information, as a repository for assisting the planning and management of building maintenance activities in sustainable building projects [11]. Additionally, BIM can establish an explicit configuration for digitized information exchange. The ability to enhance collaboration within BIM-based construction networks has been a selling point for BIM $[12,13]$. However, the technology to collaborate on models has not yet been delivered to the industry to meet BIM collaboration requirements [14]. Therefore, BIM-enabled collaboration management performs a significant part in the adoption of BIM technologies in sustainable building projects.

There have been few previous studies focusing on BIMrelated collaboration management issues. Ma et al. [15] proposed a more collaborative approach to the construction quality management process by developing a framework focused on the integrated application of BIM and indoor positioning technology. Beach et al. [16] provided an integrated BIM model to physically distribute across stakeholders to manage collaborative BIM data. Some systems are implemented for communication management in collaboration-based BIM model development. Oh et al. [17] developed an integrated, collaborative design framework for the BIM. Chen and Hou [18] developed a system to facilitate BIM modeling collaboration developments among team members. Shafiq et al. [14] reported on the results of three focus group sessions with industry professionals to analyze the user requirements for BIM collaboration. And, Shafiq et al. [19] classified and articulated features from current model collaboration systems, which are then evaluated from the user's perspective in selected model collaboration systems. Singh et al. [20] developed a theoretical framework of technical specifications for using BIM-server as a multidisciplinary collaboration platform. Isikdag and Underwood [21] proposed a system-level and BIM-based approach for 
aiding collaboration throughout the entire lifecycle of the building.

The level of BIM implementation for transport infrastructure projects has seen a substantial increase over the past two years, and development is expected to continue [22]. Recently, numerous research relating to civil and infrastructure sectors have been carried out. BIM's focus on vertical construction projects raises the probability that BIM will be used for infrastructure [23]. Cheng et al. [24] proposed frameworks to evaluate existing BIM adoption practices for various civil facilities and infrastructures. Bradley et al. [25] reviewed and evaluated BIM employment on the basis of applicable literature for infrastructure projects. Guo et al. [26] identified the Civil Information Modeling (CIM) vision and definition and developed an initial CIM implementation framework. Costin et al. [27] provided a systematic, revised literature review and critical overview of BIM research areas for transport infrastructure to promote further study and applications. There are multiple applications and implementations of BIM for road projects [28-30], airport projects [31,32], underground utilities [33, 34], and bridge projects [35-37].

Although many BIM-related systems have been developed for various requirements, few researchers have focused on information management systems for CBMDM. Many commercial collaboration management systems and software programs have been used widely in the AEC industry. However, these collaboration-based information systems were not specifically designed for BIM model development. Referring to and controlling up-to-date information and results of CBMDM works effectively is critical for BIM management to improve the performance of CBMDM tasks. Furthermore, these BIM management platforms cannot support most requirements of CBMDM tasks, although the majority of commercial BIM collaboration management software (such as Autodesk 360) support project team management and the sharing of related information for BIM model development in a single system. However, few tracking and control management functionalities have been developed for use in CBMDM. It is necessary and important to develop a system to assist effectively in CBMDM tasks. The current status and details of CBMDM tasks should be recorded and managed effectively for BIM management. Additionally, the latest information needs to be managed effectively for project participants. Therefore, this study develops a CBMDM system to reference and manage the upto-date status and information about CBMDM tasks effectively. In particular, the proposed approach and system used in this study differ from those of other existing BIM software and BIM-related information systems that have been developed.

\section{Research Method}

Based on interviews with BIM engineers and managers with five to ten years of experience in CBMDM tasks in Taiwan, the following are some of the major issues in GCs' CBMDM activities [38]:
(1) Failure to share relevant updated information with other participants, which leads to mistakes;

(2) Ineffective CBMDM performance because most CBMDM activities are recorded using paper-based documents;

(3) A lack of suitable tools for managing CBMDM activities;

(4) A lack of analysis of CBMDM implementation records making it difficult to make advanced decisions during the CBMDM process;

(5) Difficulties for on-site project engineers in obtaining accurate information on BIM issues.

Although many commercial systems have been developed for BIM model management (e.g., Autodesk 360 software), those systems are mainly designed and developed for saving different versions of the BIM model, whereas some BIM software (e.g., the Oracle Aconex collaboration platform) provides functionality for BIM model version comparison. However, few systems have been developed to improve the communication and process management of BIM models. Therefore, unlike existing BIM tools and software, the proposed system of this paper has been developed to enhance CBMDM tasks.

This study focuses on the practical implementation of CBMDM and the workflow management and control of CBMDM tasks for GCs. To enhance the workflow management and control of CBMDM tasks, the proposed CBMDM procedure encompasses the processing status, identifying status, modifying status, proofing status, and finalized status based on interviews with BIM construction professionals. Each status is outlined briefly in Table 1. To enable the BIMs manager, BIM engineers, and project engineers to track CBMDM tasks, this study proposes the following five types of process statuses for the procedures in the CBMDM system: processing status, identifying status, modifying status, proofing status, and finalized status.

According to interviews with BIM engineers and BIM managers, the following are the design requirements for the system:

(1) An ability for BIM engineers to share the latest details of the CBMDM task with BIM engineers and the BIM manager;

(2) An ability for the BIM manager to access and track the latest status and results of all CBMDM tasks;

(3) An ability for the BIM manager to assign content and checklists of the CBMDM task directly in the web environment;

(4) An ability for the BIM engineers to record and refer to the stored CBMDM task history and make comments for management purposes.

The main participants of the CBMDM process will include the BIM manager, BIM engineers, and project engineers (Figure 1). The CBMDM system is designed and developed to automatically store only the latest revision of BIM models in its master document register. The system also 
TABLE 1: The description of each status for the CBMDM procedures.

\begin{tabular}{lc}
\hline Status & Description \\
\hline Processing status & To start up for CBMDM tasks \\
Identifying status & To identify faults of CBMDM tasks \\
Modifying status & To revise faults for CBMDM tasks \\
Proofing status & To confirm and proof for CBMDM tasks \\
Finalized status & To notice modified CBMDM tasks \\
\hline
\end{tabular}

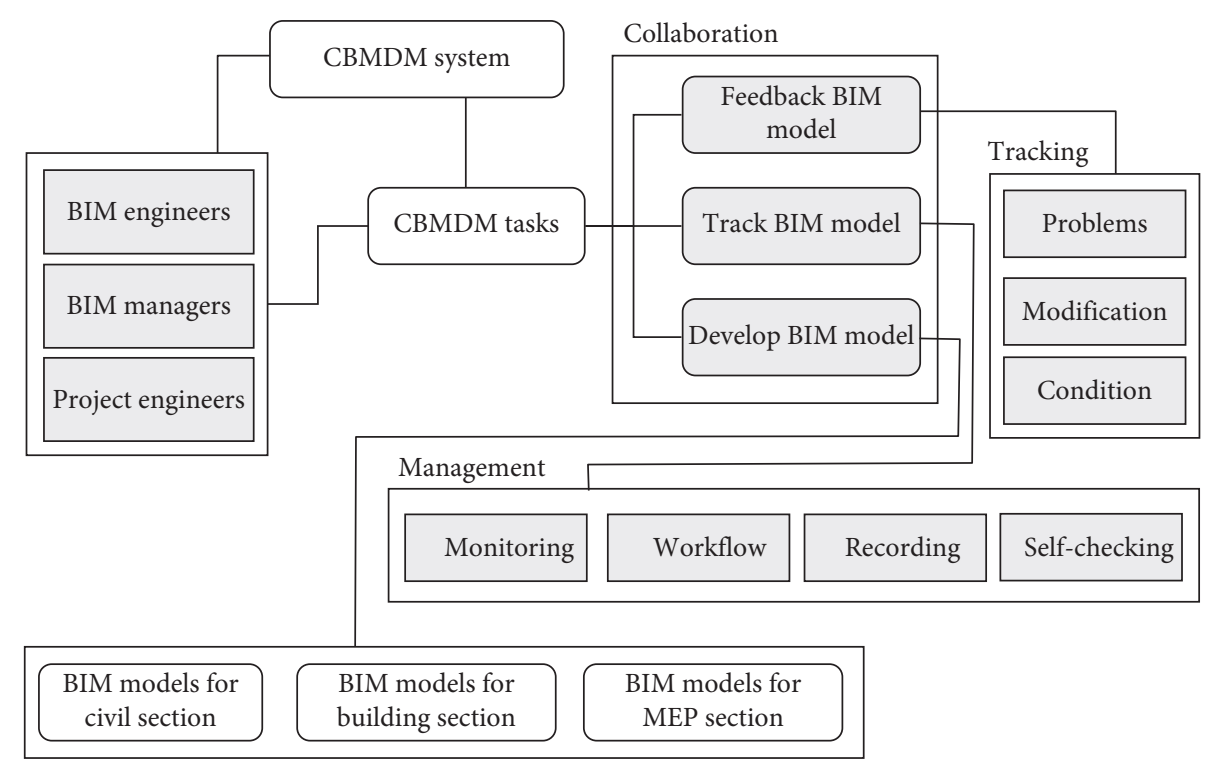

Figure 1: The concept for the proposed CBMDM system.

makes it easy to transmit the latest BIM model development revision for CBMDM to the relevant participants. The centralized management of all CBMDM tasks and related information can be tracked, recorded, communicated, and managed among relevant participants by the CBMDM system. Furthermore, BIM managers may utilize the CBMDM system to request CBMDM task updating or provide feedback to problems with CBMDM tasks to BIM engineers through the CBMDM system. Before any CBMDM task can be issued for construction, the BIM model of the CBMDM task must be internally reviewed and confirmed before it can be distributed for approval. When the revisions have been completed, the BIM manager must decide whether to approve or reject the CBMDM task. If it is rejected, the BIM model is sent back to the originator (a BIM engineer) for revision before it can be resubmitted for approval.

To enhance the performance of CBMDM works, the system references six types of CBMDM forms that are used to manage and effectively track related processes: general form, checklist form, identified problem form, request for information (RFI) form, RFI reply form, and a modification form (Figure 2). General forms are edited by BIM engineers and contain a brief description of the BIM model, such as its name, version, modeling time, and the BIM engineer's name.
To elaborate on the purpose of each form, BIM managers use the CBMDM checklist-which includes the BIM model name and version, a model description, and validation time-to appropriately handle BIM models during an inspection. BIM engineers reference the identified problem form to respond to problems identified in the CBMDM task; the form includes the model name, issues related to the identified problem, the proposed time, the project engineer's name, and the identified problematic BIM model. The RFI form provides information on the name of the BIM model, RFI contents, time, submitter's name, and RFI attachments and is used to confirm the interpretation of a detail, specification, or note on the model or to secure a documented directive or clarification from the BIM engineer. The RFI reply form is used by the BIM engineer to reply to unclear BIM models and is comprised of the name of the marked-up BIM model, a description of the unclear elements, supplementary modeling details, RFI reply contents, RFI reply time, the responder's name, and BIM-related attachments. Finally, the modification form presents the name of the revised BIM model, a detailed description of the modified BIM model, the update time, the version of the revised BIM model, and the BIM engineer's name. BIM engineers use the document to record information on the revised BIM models and, more importantly, to understand the differences 


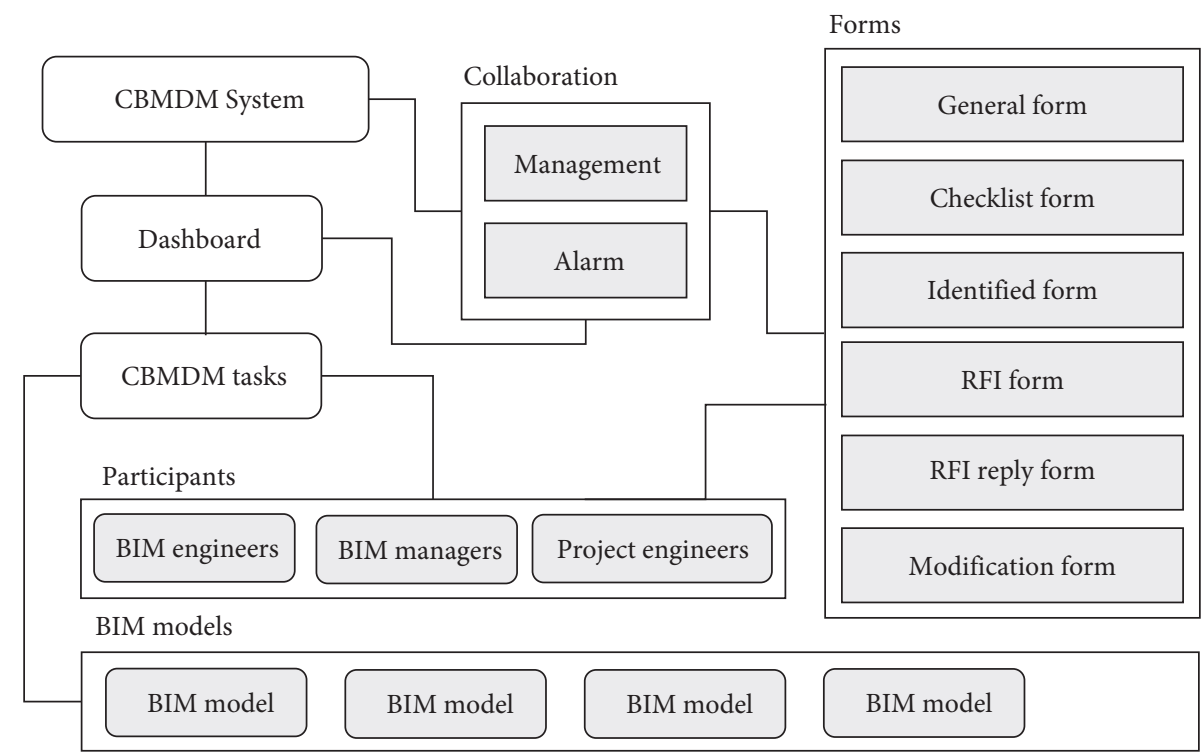

Figure 2: The usage of CBMDM forms in the CBMDM system.

between the file revisions for the BIM models. Figure 3 illustrates the proposed main flowchart for CBMDM tasks integrated with the six types of forms.

\section{System Implementation}

4.1. System Architecture. This study proposes a CBMDM system that can assist BIM engineers in exporting central BIM models into read-only BIM models (NWD files). The system then automatically uploads the exported models to the CBMDM system using an application programming interface (API). A CBMDM system user can download the NWD files for CBMDM tasks. The system automatically synchronizes the latest BIM files once a modification is made to the central BIM model. In addition, BIM engineers can save and update information on BIM components in the BIM files without directly accessing the central BIM models.

This study adopts a user-server system architecture to limit the possibility of disruptions in the operation of a BIM model. Unlike NWD files, all BIM files are stored on the system server. To access and edit central BIM models, BIM engineers need to utilize the CBMDM-API subsystem directly on the server side. CBMDM information can be accessed through the BIM files and edited via the user-side database.

The CBMDM system comprises four layers-management, data access, application, and presentation-each with its own responsibilities (Figure 4). The following section describes the distinct layers in the CBMDM system.

First, in the management layer, BIM engineers can use the BIM software to access, edit, and manage models saved on the server via the Internet. The management layer provides both the import and export of data between the central models and the NWD files integrated with the CBMDM-API subsystem. Furthermore, it is possible to link related CBMDM information with the CBMDM database in the system's management layer.
Second, the data access layer consists of the CBMDM database and the BIM files. The CBMDM database stores all detailed CBMDM records as per the element ID, whereas the NWD files save complete BIM element details (i.e., the element ID and name) in a model. The primary key is developed to connect the element ID and the index. Accordingly, complete CBMDM information can be retrieved using the element ID for data mapping using the information on the data associations.

Third, applications for the primary system-e.g., indexing, updates, and transfers of BIM model data, visualization of CBMDM status, and reports on generation functions-and API modules are defined in the application layer. The application layer applies developed API modules to integrate the BIM software used to access the BIM models. It can also automatically acquire data and analyze CBMDM tasks. Finally, the presentation layer of the CBMDM system offers location information on the models, records information for CBMDM, and automatically displays the latest CBMDM results, statuses, query history, and CBMDM result reports.

Figure 5 illustrates the system process flowchart used in the CBMDM system. When a BIM engineer finishes the BIM model development, they then need to check the BIM model themselves and submit the verified BIM model to the system. Then, the system will deliver the verified BIM model to the BIM manager. Furthermore, the dashboard will be updated to show the status of the system. The BIM manager will start to confirm the BIM model and refer to the result submitted by the BIM engineer. The BIM manager will highlight any problems in the model and send it back to the BIM engineer if there are still problems in the model. The BIM manager can integrate the BIM model with other models if necessary and announce the completion of the BIM model development to the relevant participants. Additionally, the system will record the process information for CBMDM and the 


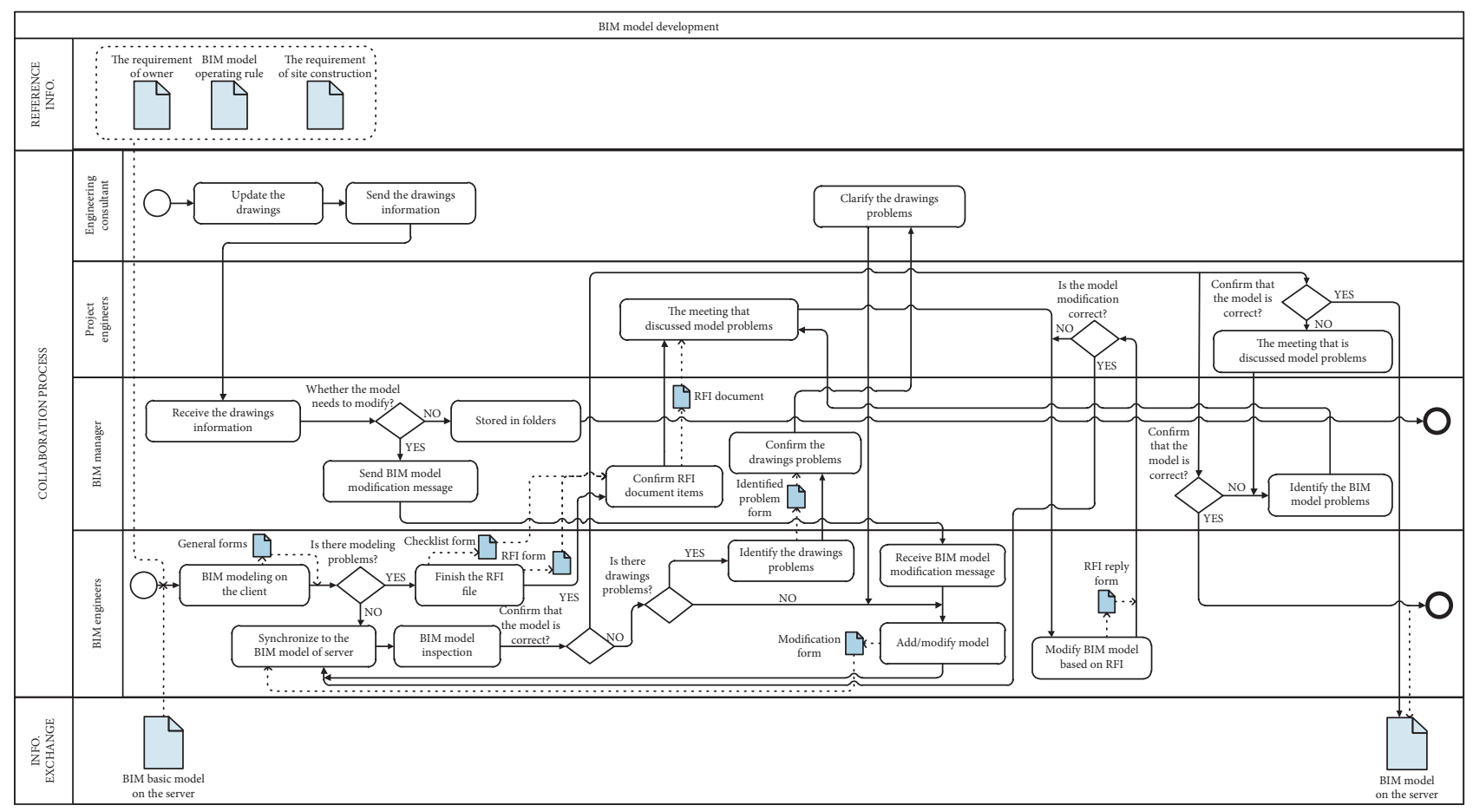

FIGURE 3: The proposed main management flowchart for CBMDM.

dashboard will be updated to display the latest result of the CBMDM tasks in the system.

The CBMDM system is designed such that it can be used by all BIM model development participants and offers a management portal that project engineers can access as a real-time, online communication channel. More specifically, the CBMDM system provides a BIM management dashboard that stores and classifies all data. It uses a database linked to the BIM models' files with access levels that vary according to a user's role. Depending on the responsibilities assigned under the CBMDM system, participants can enter and update CBMDM information. Once information about an issue is updated in the CBMDM system, the project manager, BIM engineer, and associated BIM manager are informed via an email from the server. All APIs were programmed using Visual Basic.NET utilizing the Autodesk Navisworks API. Data acquired from different systems are integrated using a program in $\mathrm{C}++$ such that BIM model files can be exported to an Open Database Connectivity (ODBC) database for connection with the CBMDM system. To maintain system performance, it is necessary to use an external location to store information derived from other applications. The CBMDM system has two databases: the BIM element database and the CBMDM database. The BIM element database stores basic information while the CBMDM database stores CBMDM information. Both databases are linked by the element ID index using data mapping. There are two API modules developed in the CBMDM system. The first is an API module to automatically convert basic information on certain BIM components into an editable format without manual data entry. A user can edit problems or leave comments by clicking on the corresponding BIM model component. The second API module allows users to save other users' current views of BIM model information (e.g., view position, direction, elevation, and zoom). Thus, it is possible to clearly understand the components of the BIM model when users click on the issue and access a $3 \mathrm{D}$ view position and direction.

4.2. System Modules. This section demonstrates the implementation of the CBMDM system modules.

4.2.1. Module for Authority Management. This module is an access control mechanism preventing unauthorized participants from entering the system or retrieving sensitive CBMDM information. As different project participants require the CBMDM information and reports, and there are variations between BIM models, this module ensures authorized participants have different access rights and authorities.

4.2.2. Module for Processes Monitoring. This module enables all relevant participants to track the processes of the CBMDM task. The module has an easy-access option that allows participants to track and record the status and information of the CBMDM task online. Furthermore, BIM engineers and project engineers can refer to the responses and information on the most recently revised BIM models.

4.2.3. Module for Alert Management. This module helps the BIM manager, BIM engineers, and project engineers set up an alert service via email for monitoring and managing the 


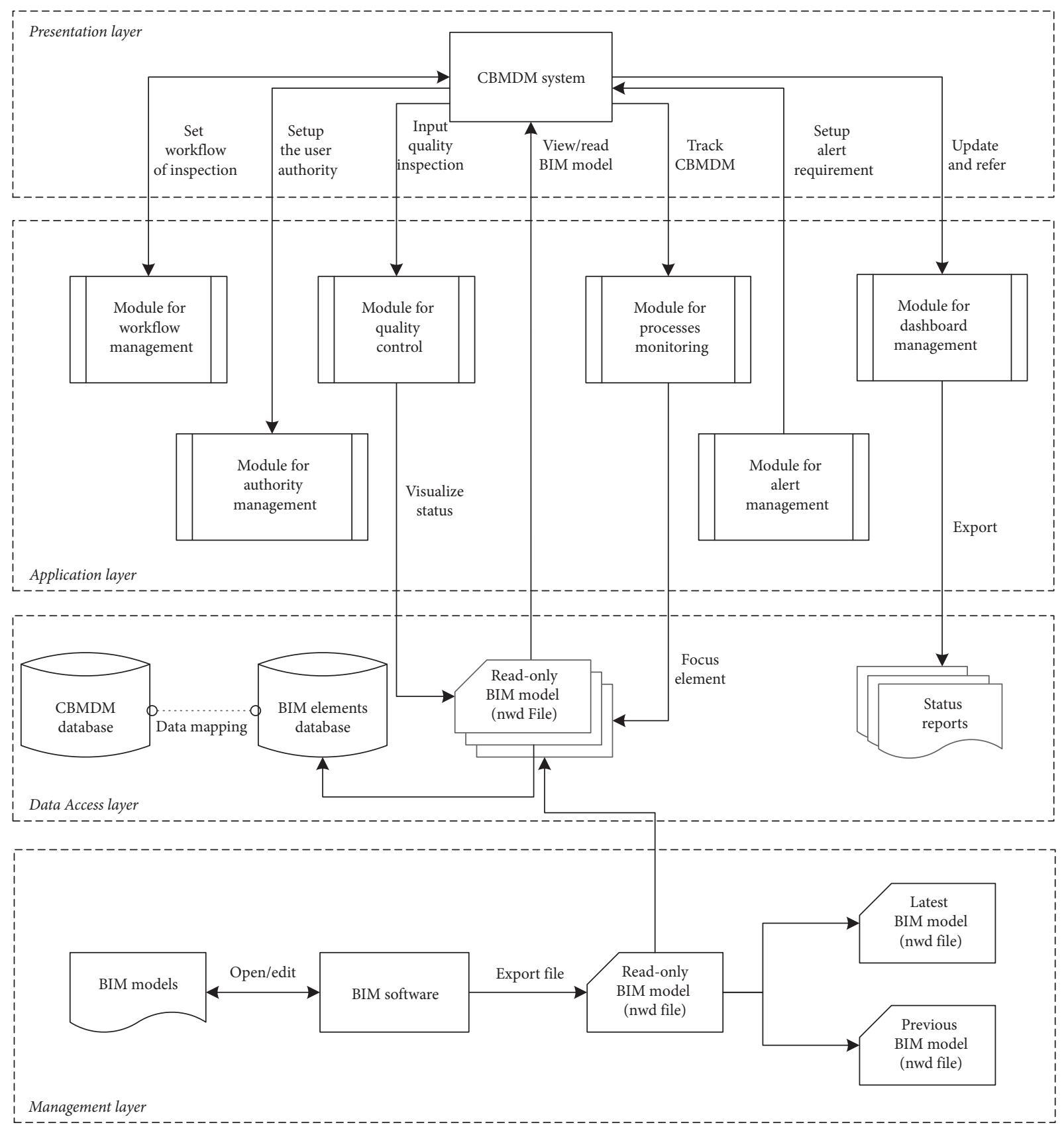

Figure 4: The system framework of the CBMDM system.

CBMDM task. Dates related to notifications of updated CBMDM information are recorded systematically, thus enabling the BIM manager to determine who is responsible for specific CBMDM tasks.

4.2.4. Module for Workflow Management. This module lets users create the workflow of the CBMDM task. All the required steps can be set up in the module. Once each step of the CBMDM task is confirmed, the results of CBMDM are sent to the relevant participants, and the process moves to the next stage based on the initial workflow setup. All related information, records, and comments are saved in the system for future reference. For the CBMDM task, the characteristics of this module are unique as compared with currently used BIM management software and systems.

4.2.5. Module for Quality Control. This module allows the BIM manager to input the inspection results (such as a checklist) and comments for the unconfirmed BIM models. After the inspection of a BIM model, the responsible BIM engineer can modify the model based on the comments and resubmit the modified model to the system for confirmation. The system saves all inspection and modification records and comments for quality control of CBMDM tasks. 


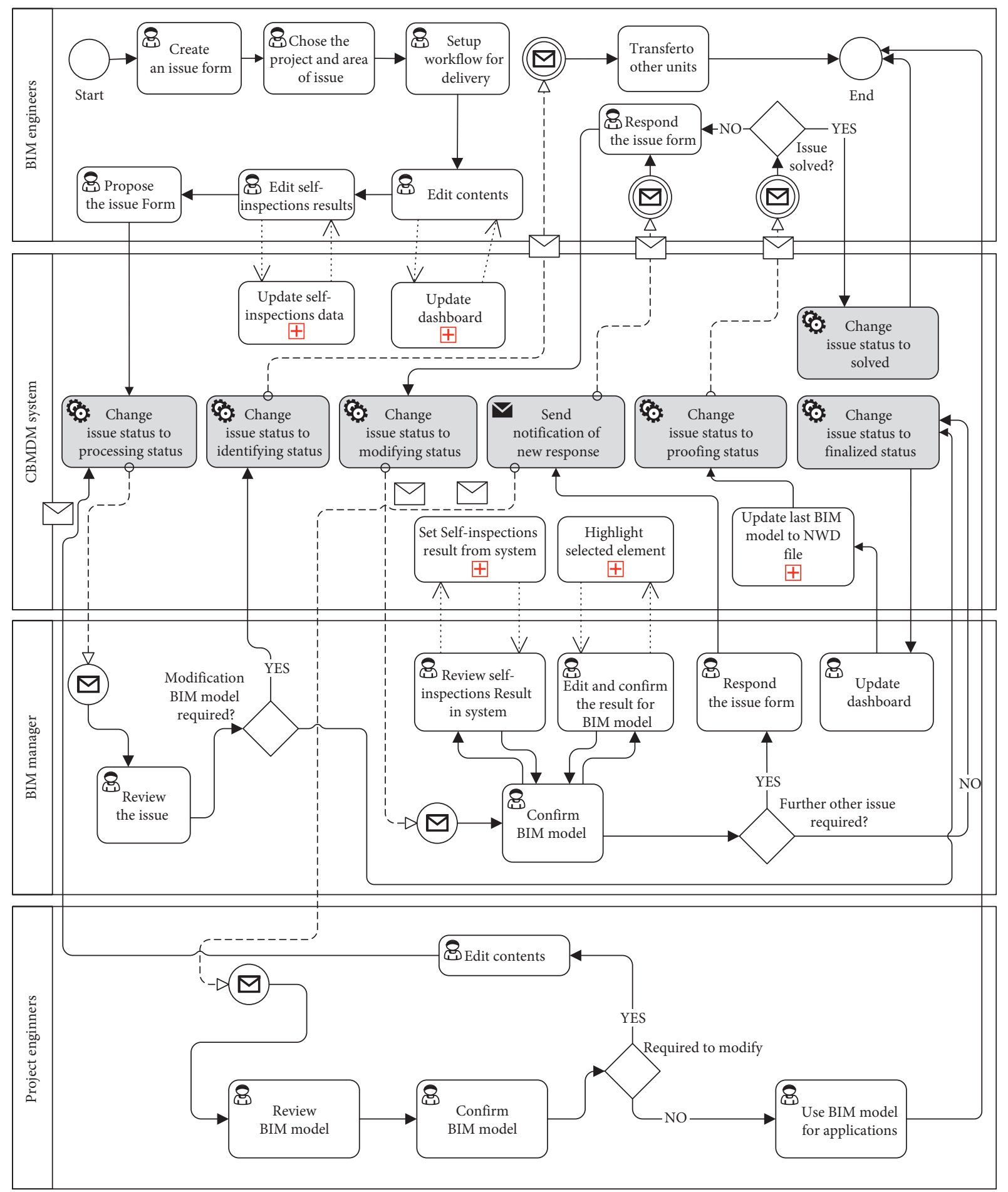

FIGURE 5: The system process flowchart used in the CBMDM system.

4.2.6. Module for Dashboard Management. This module allows project engineers, BIM engineers, and the BIM manager to track the latest results and access visual representations of the CBMDM task. The proposed BIM dashboard in the CBMDM system is designed for performing the CBMDM task. It enables all authorized users to refer to and check the latest statuses of all CBMDM tasks. The BIM dashboard is a visual representation of the CBMDM task based on the CBMDM status. Furthermore, BIM managers can access statistics and results from information stored in the CBMDM system.

\section{Case Study}

5.1. Case Description. This study examines the case of a GC with over twenty years of experience in the implementation 
of MRT projects in Taiwan. Owing to serious low performance issues regarding the use of email for CBMDM tasks, the GC decided to adopt a CBMDM system. In addition, the GC assigned project engineers, BIM engineers, and a BIM manager to access the CBMDM system to enhance performance for CBMDM tasks during the construction phase of an MRT project.

In the initial phase, the BIM manager and BIM engineers (from three civil, building, and mechanical, electrical, and plumbing (MEP) sections) identify requirements and plans for the development of major BIM models for an MRT project. The BIM engineers use Autodesk Revit to create their BIM models. The BIM manager edits the summary information comprising brief descriptions of all CBMDM participants and basic information on the CBMDM task. In addition, the BIM manager defines rules and workflow structure for the initial phase of the CBMDM system. All initial BIM models are transferred to a markup-enabled BIM model for all project engineers, who, in turn, submit the original BIM model to the system for approval. Prior to the publishing of the BIM models for project engineers, the BIM models are subject to a proofing phase in which they are confirmed and proofed by BIM managers. Once the models are approved, the system updates the status and results for each model of the CBMDM task.

Next is the implementation phase, during which the BIM manager and BIM engineer for each building section identify errors and, accordingly, offer suggestions in the CBMDM system. In addition, the BIM manager communicates problems and mistakes in the model to the BIM engineers for the civil and MEP sections. Upon receiving feedback from the BIM manager and the BIM engineer responsible for the building section, the BIM engineers for the civil and MEP sections update their modified BIM model based on the comments. All records of the CBMDM task during this phase are continually saved and tracked. The CBMDM system highlights incomplete processes in red and pushes these requests back into the system. In this manner, BIM managers, BIM engineers from the three different sections, and the associated project engineers can track and manage the completion of CBMDM tasks. The BIM manager can respond through comments and requests for modifications to the BIM model and provide updated BIM comments and feedback for the BIM model. The BIM engineer who receives the manager's feedback modifies the models and updates the related information in the CBMDM system. Following any change, the modified BIM models are updated and shared with BIM engineers.

Once the BIM engineer or project engineer identifies the BIM model processes as complete, in the final phase, the BIM engineer submits the final modified BIM models and requests a closure confirmation from the project engineer. The BIM manager then confirms the final modified BIM model. Furthermore, the final step is updating the CBMDM task status in black on the BIM dashboard, with a notice subsequently emailed to the BIM manager, BIM engineers, project engineers, and authorized participants. Figure 6 shows the integrated MRT BIM models in the case study. Figure $7(\mathrm{a})$ illustrates the integrated model of the underground pipelines and depot building. Additionally, Figure 7(b) displays the integrated model of the MRT tunnel and depot building. Finally, Figure 8 demonstrates the use of the CBMDM system in the case study.

5.2. Results and Discussion. During the field testing in this study, all participants (the BIM manager, BIM engineers from the three different sections, and the project engineers) were encouraged to use the CBMDM system to track the performance of their CBMDM tasks. Figure 9 demonstrates the results of problems related to the reworking of BIM models during the collaborative work. As shown in the figure, most respondents reported rework problems for model development inconsistencies (34\%), reworking for conflict problems of models integrated with different sections (25\%), and reworking for development of models that do not meet requirements (21\%). Fewer respondents identified rework problems for required nongeometric data entry for model development (13\%) and reworking for model development because of change order requirements (7\%).

Figure 10 displays the percentages of problems in the case study for the CBMDM tasks. As shown in the figure, the majority of respondents reported difficulties in maintaining adequate time for model development (25\%), difficulties of having sufficient time for model inspection and confirmation (19\%), difficulties of having sufficient knowledge for model inspection (18\%), difficulties of having sufficient manpower for model inspection (17\%), and difficulties of having appropriate time to update and modify the model (13\%). By contrast, few respondents reported difficulties in obtaining sufficient incentives for CBMDM implementation (8\%).

To examine system function, the field testing included a verification test in determining whether the system performs tasks in line with its design and validation checks in order to evaluate system utility. During the validation test, select case participants used the system, and project teams provided feedback through a questionnaire. The participants were five BIM engineers under a GC with five years of experience, three BIM managers with ten years of experience, and five project managers with eight years of experience. System function and user satisfaction with the system's capabilities were evaluated using questionnaires. The CBMDM system's functionality and effectiveness were verified using two evaluation measures: system usage and capability. System users were asked to separately rate system usage and capability by comparing them with the previous paper-based approach on a five-point Likert scale, where 1 denotes "not useful" and 5 is "very useful." The participants were also asked to provide feedback for possible improvements to the system and offer their opinions using the questionnaire. Table 2 shows the results of system testing. Tables 3 and 4 show the participants' evaluation comments on system testing.

The following are the highlighted major advantages of the CBMDM system based on the questionnaire results:

(1) The CBMDM system allows BIM engineers and managers to track and manage CBMDM information during the task processes (95\% agreed). 

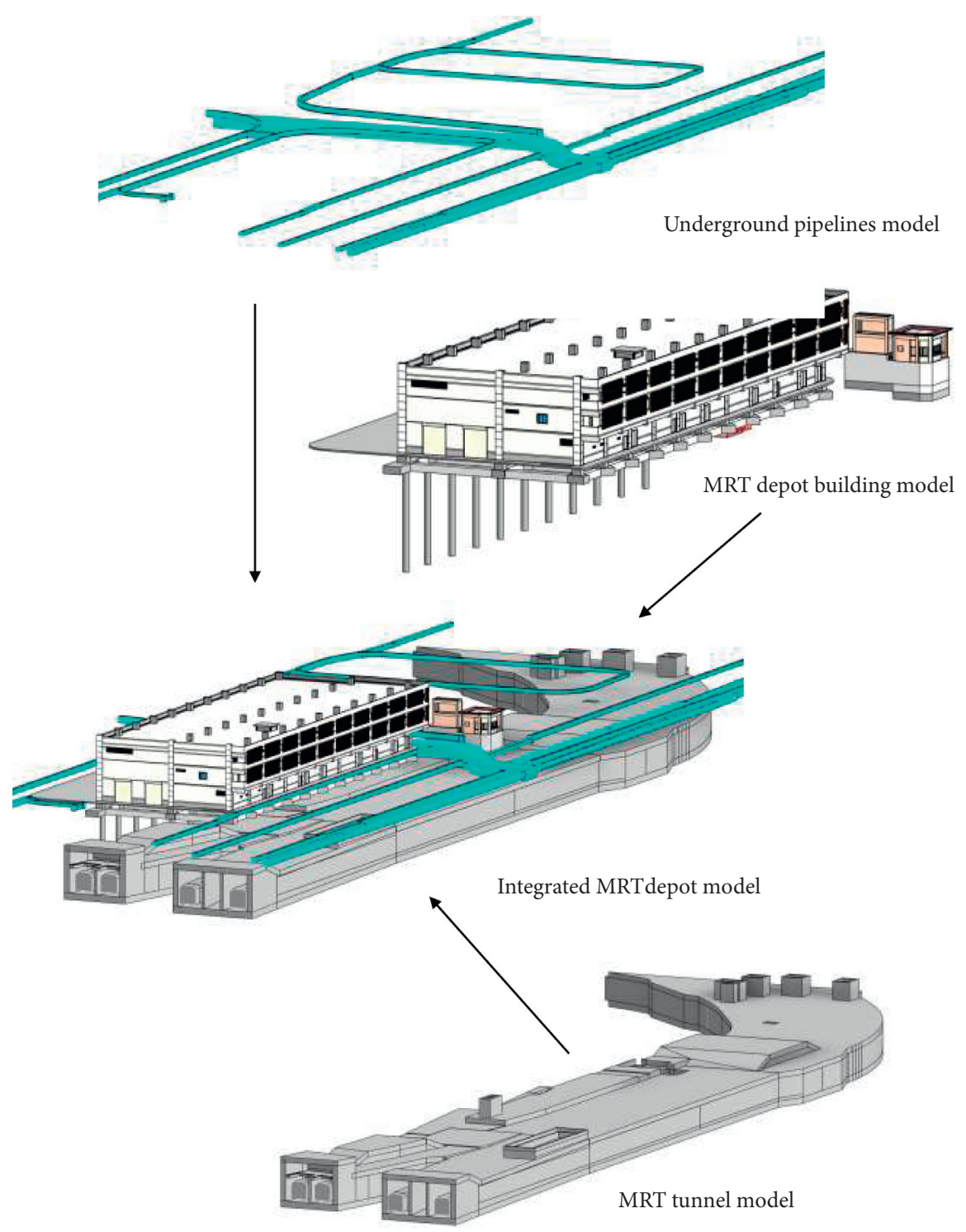

Figure 6: The integrated BIM model of the CBMDM task.

(2) The CBMDM system allows BIM engineers to provide feedback on the errors and problems for CBMDM (88\% agreed).

(3) The CBMDM system enables BIM engineers to track the newest versions and determine the status of CBMDM tasks (93\% agreed).

(4) The BIM dashboard identifies available CBMDM information for tracking ( $86 \%$ agreed).

(5) The CBMDM system improves the ease and effectiveness of managing modifications to the model versions in the Internet environment (92\% agreed).

The following limitations, barriers, and suggestions were identified for the use of the CBMDM system:

(1) Although the use of the CBMDM system can help BIM engineers and managers to implement CBMDM tasks effectively, suitable management mechanisms for the CBMDM tasks should be developed by the BIM managers in the beginning. Without suitable management mechanisms for CBMDM tasks, the CBMDM system cannot provide an effective solution for CBMDM tasks.

(2) It is necessary to inspect collaboration-based BIM model development before the BIM implementation. It will take time for BIM managers to handle the inspection tasks for all BIM models. Therefore, it is necessary and important to let BIM engineers handle self-inspections for BIM models first before the BIM model is submitted to the BIM manager. The CBMDM system can record the inspection result as edited by BIM engineers and let BIM managers access the inspection result records based on the selected BIM model.

(3) It is suggested that BIM managers should encourage all BIM engineers to use the CBMDM system during the process. Without encouragement from 


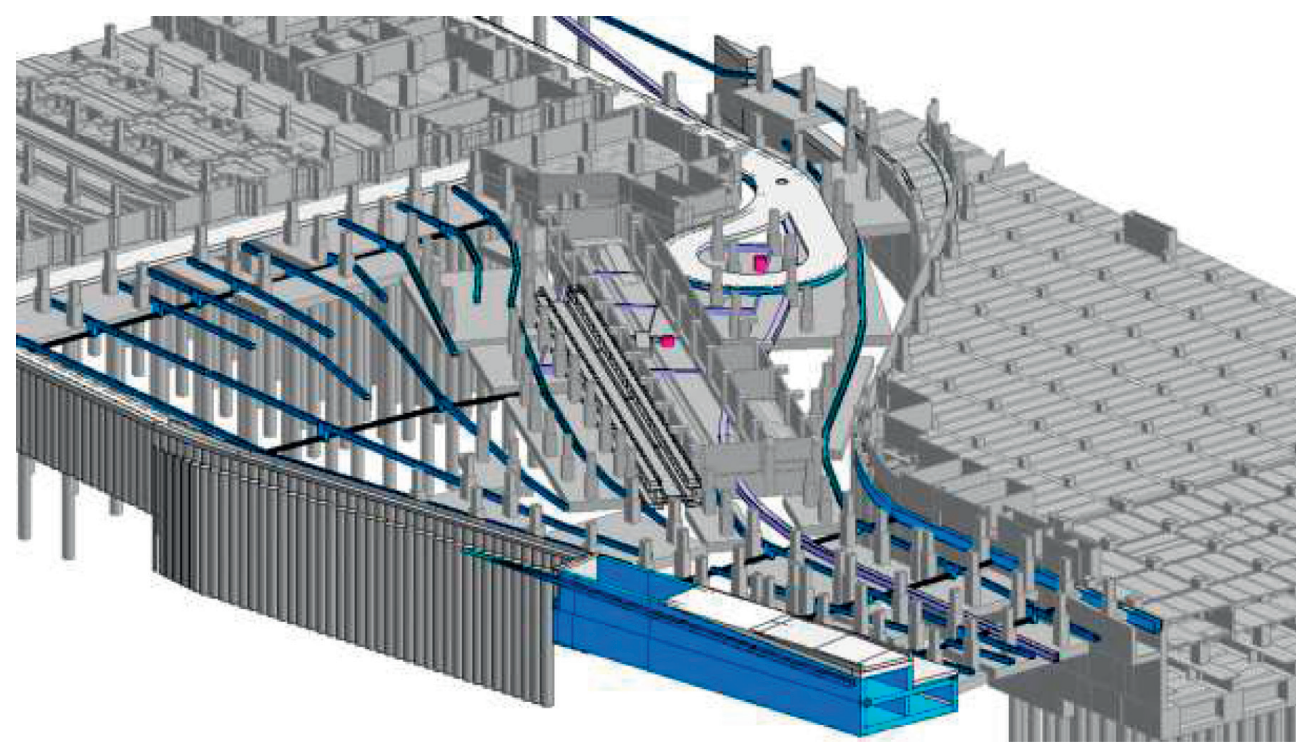

(a)

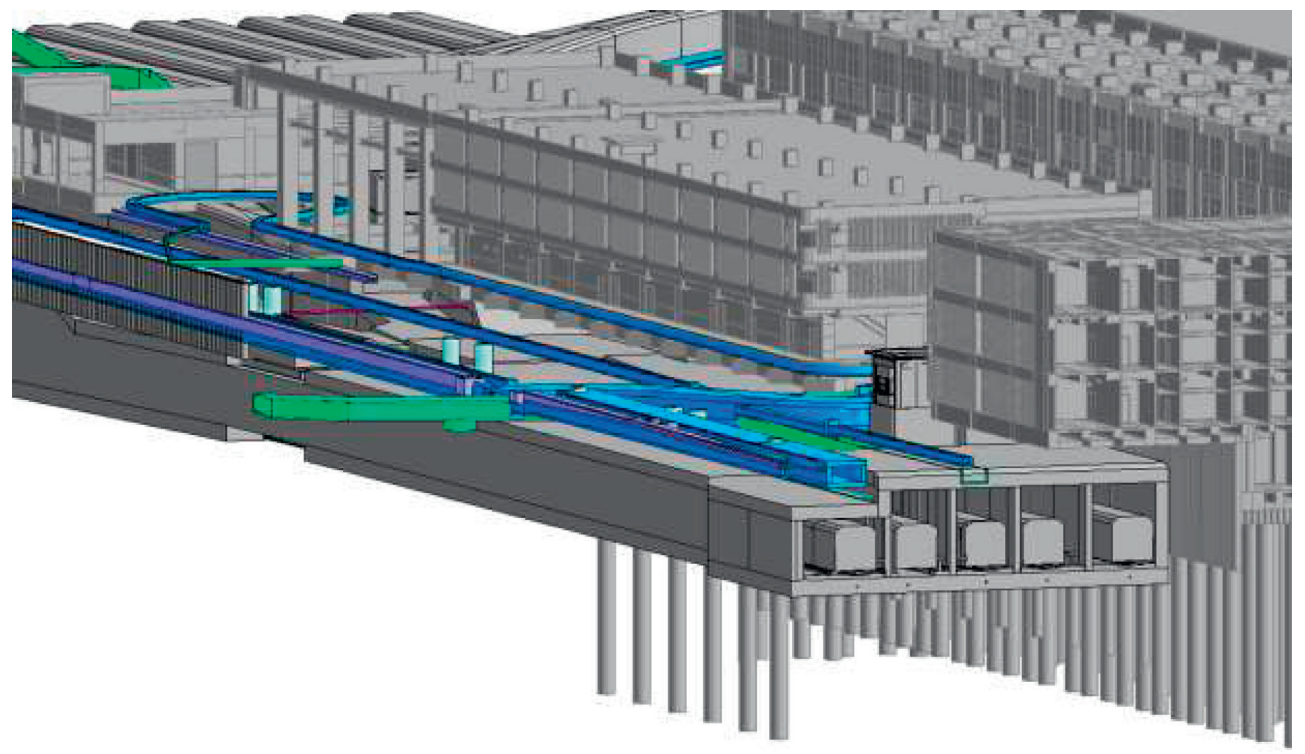

(b)

FIGURE 7: The integrated MRT BIM model in the case study. (a) The integrated BIM model for underground pipelines and depot building. (b) The integrated BIM model for the MRT tunnel and depot building.

the BIM manager, most BIM engineers may use different systems (such as Line, the instant communications software) for information exchange. However, the information and attached files in those systems are not easy and effective for management. Therefore, it is necessary to encourage all $\mathrm{BIM}$ engineers to use the CBMDM system for effective CBMDM.
The major recommendations based on user feedback are summarized as follows:

(1) The support of BIM managers is necessary for successful CBMDM implementation.

(2) A development strategy must be proposed to encourage the utilization of the CBMDM system by relevant participants for CBMDM tasks. 
The area to edit topic and select respond participants on the CBMDM

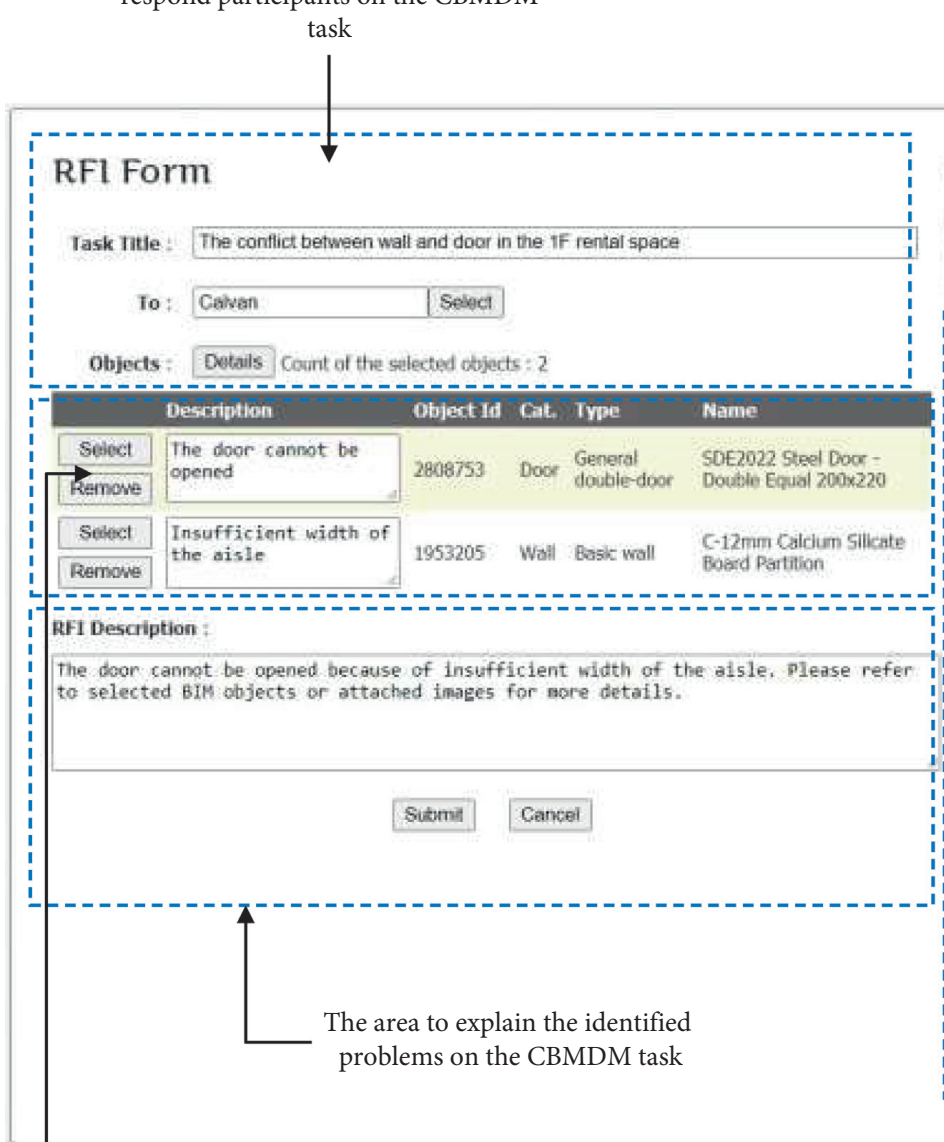

The area to show screenshot of BIM model for problems on the CBMDM task

\section{Images for RFI}

Choose File No file chosen

itrage Descriphon

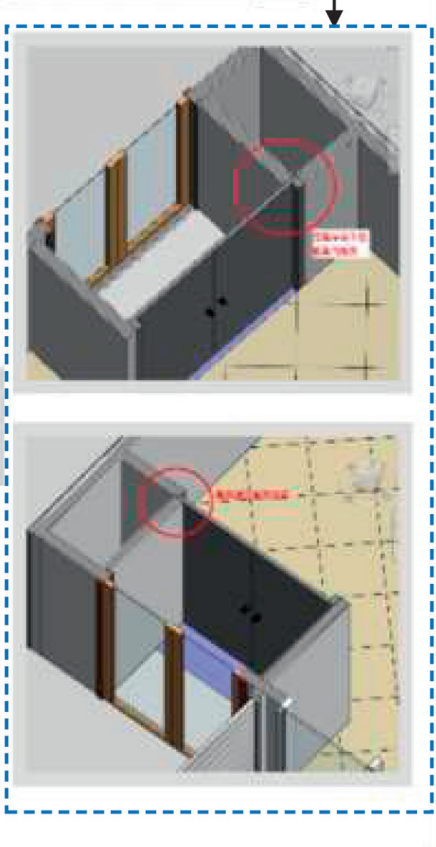

The area to show the identified BIM

model with problem based on the topic ofthe CBMDM task

FIgure 8: The use of the CBMDM system for CBMDM work in the case study.

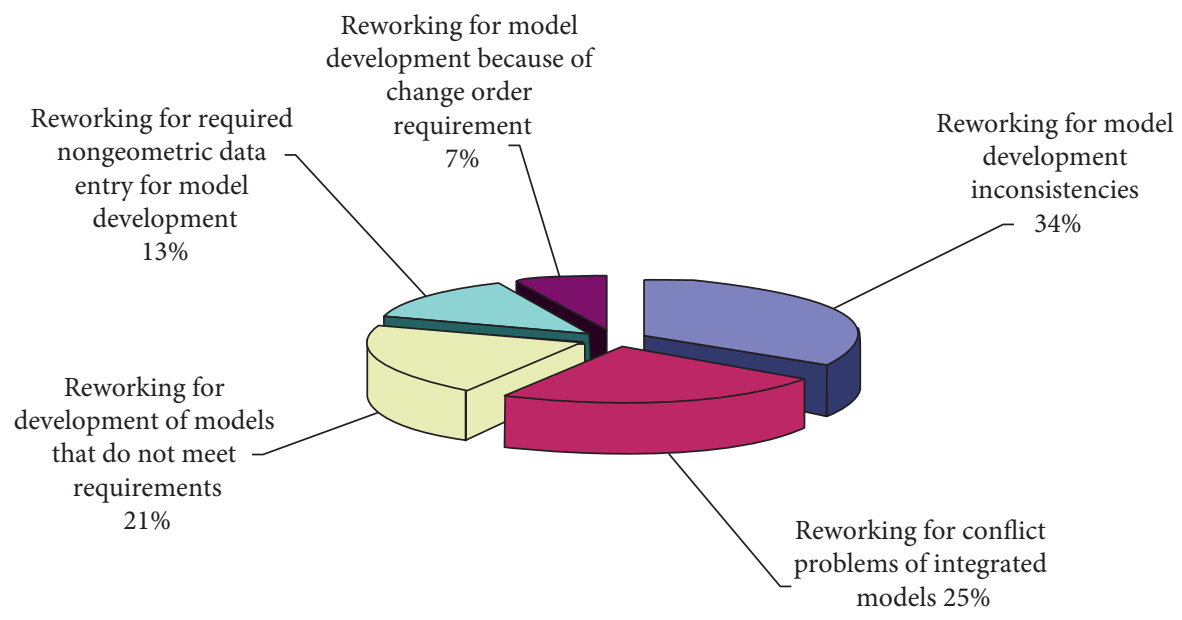

FIGURE 9: The major problems related to the reworking of BIM models development during the collaborative work. 


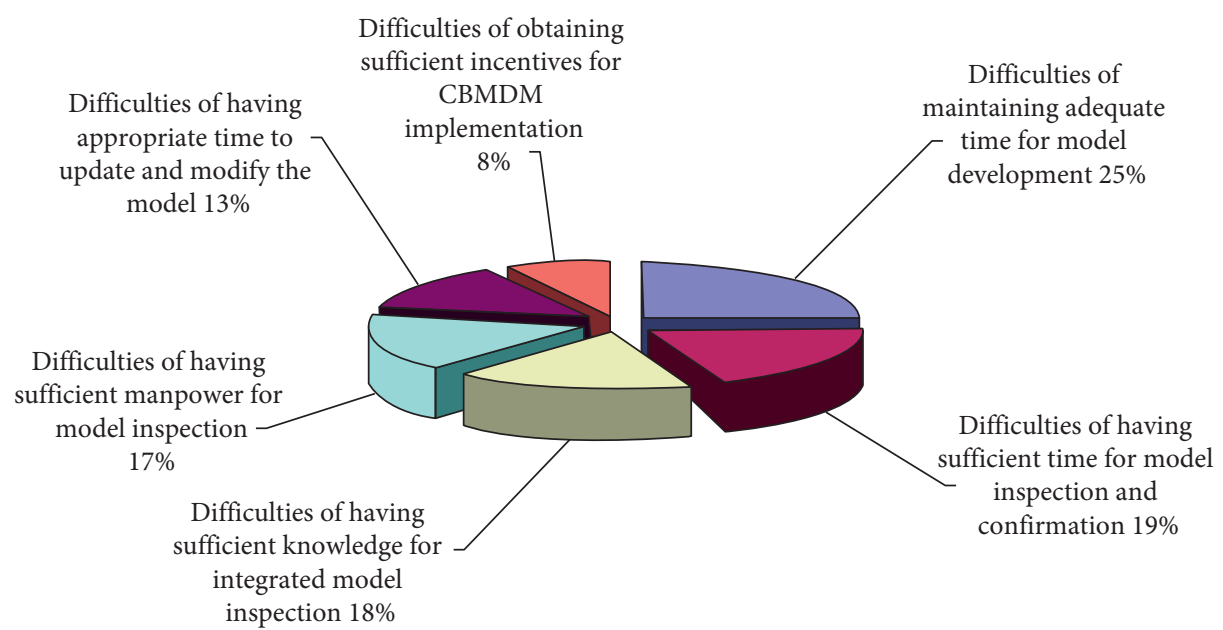

FIgURE 10: The major problems for CBMDM tasks in the case study.

TABLE 2: System evaluation result.

\begin{tabular}{lcc}
\hline System usage & Standard deviation & Average rating \\
\hline Ease of effective communication for CBMDM tasks & 0.63 & 4.7 \\
User interface & 0.52 & 4.5 \\
Willingness to utilize the system for CBMDM tasks & 0.53 & 4.3 \\
Ease of use & 0.63 & 4.5 \\
System capability & & 4.6 \\
Reduces CBMDM rework & 0.52 & 4.3 \\
Ease of finding information about CBMDM tasks & 0.47 & 4.6 \\
Improves problems tracking for CBMDM tasks & 0.52 & 4.5 \\
Enhances monitoring of CBMDM tasks & 0.43 & 4.5 \\
Enhances workflow management of CBMDM tasks & 0.52 & 4.6 \\
Reduces sharing problems of CBMDM tasks & 0.43 & 4.1 \\
Illustrates and understands CBMDM tasks clearly & 0.41 & 4.5 \\
Addresses complete records of CBMDM tasks & 0.42 & \\
\hline
\end{tabular}

Note: The mean score is calculated from respondents' feedback fivescale questionnaire: 1(Strongly disagree), 2, 3, 4, and 5 (strongly agree).

TABLE 3: Evaluation comments from participating BIM engineers.

\begin{tabular}{|c|c|}
\hline No & Participant comments \\
\hline 1 & $\begin{array}{l}\text { I felt that one of the biggest advantages was that the CBMDM system retains the history records for all communication regarding the } \\
\text { components of BIM models. I found it very helpful to find and refer to the necessary information during the task process. }\end{array}$ \\
\hline 2 & $\begin{array}{l}\text { Using the CBMDM system, I can access input the information for the CBMDM tasks and refer directly to the CBMDM-related results. } \\
\text { It is more convenient for me than the current email method. }\end{array}$ \\
\hline 3 & $\begin{array}{l}\text { It is useful for me to manage all the current results and trace all ongoing CBMDM tasks easily and effectively by using the CBMDM } \\
\text { system. The CBMDM system is more convenient and helpful than the current email system. }\end{array}$ \\
\hline 4 & $\begin{array}{l}\text { I used email to access and trace the latest result of the CBMDM tasks. Now, I trace and manage the newest status of CBMDM tasks } \\
\text { quickly using the CBMDM system. The CBMDM system provides great assistance to us to communicate and discuss CBMDM tasks } \\
\text { effectively. }\end{array}$ \\
\hline 5 & $\begin{array}{l}\text { The CBMDM system allows us to respond to all the current ongoing problems of CBMDM tasks and access all the unfinished } \\
\text { CBMDM results quickly and easily. }\end{array}$ \\
\hline 6 & $\begin{array}{l}\text { The CBMDM system can record all history communication information regarding the issues related to CBMDM tasks. It is very useful } \\
\text { and helpful for me to find and refer to the required information based on the selected issue of CBMDM tasks. The CBMDM system } \\
\text { differs from other existing BIM-related systems. }\end{array}$ \\
\hline 7 & $\begin{array}{l}\text { I can refer to the statistical analysis results of the CBMDM tasks directly through the CBMDM system. It is very helpful and important } \\
\text { for me to handle CBMDM tasks effectively. }\end{array}$ \\
\hline 8 & $\begin{array}{l}\text { I like to have an overview and track the status and results of CBMDM tasks by the dashboard of the CBMDM system. The use of the } \\
\text { dashboard is more useful for management than my previous email method. }\end{array}$ \\
\hline
\end{tabular}


TABLE 4: Evaluation comments from participating BIM managers.

\begin{tabular}{|c|c|}
\hline No & Participant comments \\
\hline 1 & $\begin{array}{l}\text { During the process, all ongoing CBMDM tasks can be tracked and managed easily and effectively through the CBMDM system. I think } \\
\text { that the CBMDM system will be more convenient and helpful than the email system. }\end{array}$ \\
\hline 2 & $\begin{array}{l}\text { The CBMDM system let me obtain related CBMDM tasks effectively. It helps me a lot to handle the problems and responses to the } \\
\text { CBMDM issues. }\end{array}$ \\
\hline 3 & $\begin{array}{l}\text { I used email to manage all CBMDM tasks. Now, I prefer to check and manage the newest status of responses to the CBMDM task } \\
\text { quickly and effectively. }\end{array}$ \\
\hline 4 & $\begin{array}{l}\text { The CBMDM system can record all historic communication information regarding the issues of CBMDM tasks. It is very useful and } \\
\text { helpful for me to find and refer to the necessary information based on selected issues. This proposed CBMDM system is different from } \\
\text { existing BIM software. }\end{array}$ \\
\hline 5 & $\begin{array}{l}\text { One of the biggest advantages I felt was that the CBMDM system stores the records of communication regarding the components of } \\
\text { the BIM models, which was very helpful for me to find and refer to the necessary information during the process. }\end{array}$ \\
\hline 6 & $\begin{array}{c}\text { Although there are many limitations of CBMDM tasks in practice, the development of the CBMDM system is to meet the practical } \\
\text { requirements of CBMDM tasks. }\end{array}$ \\
\hline 7 & $\begin{array}{c}\text { I can respond to all the current ongoing issues related to CBMDM tasks and access all the unfinished CBMDM results effectively } \\
\text { through the CBMDM system. }\end{array}$ \\
\hline & $\begin{array}{l}\text { The CBMDM system allowed me to communicate with engineers about selected components of the BIM model and discuss problems, } \\
\text { that was very effective for us during the CBMDM process. }\end{array}$ \\
\hline
\end{tabular}

(3) Suitable standard operating procedures for CBMDM tasks should be developed in advance to enhance the operation progress of CBMDM tasks.

(4) Further training and workshops on the CBMDM system should be provided for all participants.

(5) The use of CBMDM can save a significant amount of time for BIM model development. However, the methodology of CBMDM work is more complicated than that of BIM model development alone. Therefore, prework planning is very important for CBMDM. For example, the rules for CBMDM tasks need to be implemented in advance to avoid unnecessary problems in CBMDM tasks during the development process.

(6) According to the case study, a BIM engineer's ability to engage in responsible, collaborative work should not be poor as otherwise, CBMDM task efficiency would be affected and decreased. There were two junior BIM engineers involved in work for CBMDM in the case study. Due to their limited BIM skills in developing BIM models, more effort was required by senior BIM engineers to verify the correctness and modifications of the BIM models. It is therefore recommended that BIM engineers with considerable BIM experiences will be more appropriate for the collaborative development of the BIM model.

\section{Conclusions}

The characteristics of infrastructure projects (such as the MRT project) include large scopes, long durations, complex interfaces, significant requirements for management, and complicated coordination and cooperation. Integrated BIM technology will be necessary and helpful in improving construction management because of the complexity of these projects. For MRT projects, collaboration-based BIM model development for GCs typically involves participants from different fields during the construction phase.
However, collaboration-based BIM model development tasks often create numerous practical problems. Therefore, effective CBMDM is important for GCs to obtain accurate BIM models before the implementation of BIM-related applications.

This paper discussed the management of collaborative BIM model development during the construction phase. A novel CBMDM system for GCs was developed to support CBMDM. Through an Internet-based environment, the CBMDM system enables BIM managers and engineers to access updated content and facilitates an updating approach and platform for CBMDM tasks. CBMDM requires effective control, especially for large-scale infrastructure MRT projects. One management challenge is that BIM managers and engineers come from different departments and different offices. In general, related information for collaborationbased BIM model development work is all stored in a decentralized location, and the control efficiency for CBMDM is not high. Therefore, a centralized managementbased platform is needed to assist all participants in CBMDM work. With the proposed CBMDM system, the performance and effectiveness of CBMDM can be enhanced and improved for infrastructure projects.

The system also assists GCs with implementing CBMDM tasks effectively and improves the sharing and tracking efficiency for CBMDM tasks. The CBMDM system also provides BIM managers and engineers with a clear audit trail by tracking and controlling updates for CBMDM tasks. Furthermore, project participants can access and utilize the most recently updated models for BIM applications during the construction phase. The collaboration management information of BIM model development can be analyzed, traced, and managed in realtime among participants. The CBMDM system is different from existing current BIM-related systems, as it has been developed with a particular goal to meet the requirements of CBMDM.

Finally, the proposed CBMDM system was applied to a case study of an MRT project in Taiwan to verify its efficacy 
and demonstrate its effectiveness for CBMDM tasks. The case study results demonstrate that the CBMDM system provides centralized storage of all collaboration management information for BIM model development during the construction phase of the MRT project, such that the BIM manager, BIM engineers, and project engineers can effectively track and manage the status of modified BIM models and update the BIM models. Overall, the field-test results showed that the CBMDM system is a useful and effective platform for GCs to handle CBMDM tasks effectively in an MRT project. Furthermore, the proposed CBMDM system is not only suitable for MRT projects but can also be utilized for other types of large-scale infrastructure projects for CBMDM.

The next phase of the research will aim to successfully implement the proposed approach and test the system in practice. In the future, the functionalities of the CBMDM system can be enhanced and integrated for advanced analysis functionalities for CBMDM tasks. Furthermore, the applications of BIM can be integrated with visual dashboard technologies for effective collaboration management during the project. The CBMDM system with visual dashboard technologies will be integrated with facility management to let users track and manage the maintained BIM models for infrastructure projects.

\section{Data Availability}

The data used to support the findings of this study are available from the corresponding author upon request.

\section{Conflicts of Interest}

The authors declare no conflicts of interest.

\section{Acknowledgments}

The authors would like to acknowledge the Ministry of Science and Technology, Taiwan, for financially supporting this work under contract no. MOST-106-2221-E-027-020 and express their appreciation to all involved project participants for their assistance in the system design and development.

\section{References}

[1] J. E. Taylor and P. G. Bernstein, "Paradigm trajectories of Building Information Modeling practice in project networks," Journal of Management in Engineering, vol. 25, no. 2, pp. 69-76, 2009.

[2] D. Migilinskas, V. Popov, V. Juocevicius, and L. Ustinovichius, "The benefits, obstacles and problems of practical BIM implementation," Procedia Engineering, vol. 57, pp. 767-774, 2013.

[3] B. Ilhan and H. Yaman, "BIM and sustainability concepts in construction projects: a case study. sb13 oulu: sustainable procurement in urban regeneration and renovation; Northern Europe and North-West Russia," 2013, https://www.irbnet. de/daten/iconda/CIB_DC26632.pdf.
[4] B. Hardin, BIM and Construction Management, Indianapolis: Proven Tools, Methods, and Workflows, Wiley Publishing Inc., Indianapolis. IN, USA, 2009.

[5] J. W. Fountain, "Outsourcing of building information modeling (BIM) among general contractors in the United States," Honors Theses, vol. 21, p. 435, 2016, http://aquila.usm. edu/honors_theses/435.

[6] S. Azhar, "Building information modeling (BIM): trends, benefits, risks, and challenges for the AEC industry," Leadership and Management in Engineering, vol. 11, no. 3, pp. 241-252, 2011.

[7] National Institute of Building Sciences (NIBS), "National building information modeling standard," 2007, http://www. 1stpricing.com/pdf/NBIMSv1_ConsolidatedBody_Mar07. pdf.

[8] C. M. Eastman, C. Eastman, P. Teicholz, R. Sacks, and K. Liston, BIM Handbook: A Guide to Building Information Modeling for Owners, Managers, Designers, Engineers and Contractors, John Wiley \& Sons, Hoboken, NJ, USA, 2nd edition, 2011.

[9] M.-H. Tsai, M. Mom, and S.-H. Hsieh, "Developing critical success factors for the assessment of BIM technology adoption: Part I. Methodology and Survey," Journal of the Chinese Institute of Engineers, vol. 37, no. 7, pp. 845-858, 2014.

[10] W. Lu, D. Zhang, and S. M. Rowlinson, "BIM Collaboration: A Conceptual Model and its Characteristics," in Proceedings of the 29th Annual Association of Researchers in Construction Management (ARCOM) Conference, pp. 25-34, London, UK, October 2013.

[11] R. Volk, J. Stengel, and F. Schultmann, "Building Information Modeling (BIM) for existing buildings-literature review and future needs," Automation in Construction, vol. 38, pp. 109127, 2014.

[12] D. Cao, H. Li, G. Wang, and T. Huang, "Identifying and contextualising the motivations for BIM implementation in construction projects: an empirical study in China," International Journal of Project Management, vol. 35, no. 4, pp. 658-669, 2017.

[13] M. Oraee, M. R. Hosseini, E. Papadonikolaki, R. Palliyaguru, and M. Arashpour, "Collaboration in BIM-based construction networks: a bibliometric-qualitative literature review," International Journal of Project Management, vol. 35, no. 7, pp. 1288-1301, 2017.

[14] M. T. Shafiq, J. Matthews, and S. Lockley, "A study of BIM collaboration requirements and available features in existing model collaboration systems," Journal of Information Technology in Construction (ITcon), vol. 18, pp. 148-161, 2013.

[15] Z. Ma, S. Cai, N. Mao, Q. Yang, J. Feng, and P. Wang, "Construction quality management based on a collaborative system using BIM and indoor positioning," Automation in Construction, vol. 92, pp. 35-45, 2018.

[16] T. Beach, I. Petri, Y. Rezgui, and O. F. Rana, "Management of collaborative BIM data by federating distributed BIM models," Journal of Computing in Civil Engineering, vol. 31, no. 4, Article ID 04017009, 2017.

[17] M. Oh, J. Lee, S. W. Hong, and Y. Jeong, "Integrated system for BIM-based collaborative design," Automation in Construction, vol. 58, pp. 196-206, 2015.

[18] H.-M. Chen and C.-C. Hou, "Asynchronous online collaboration in BIM generation using hybrid client-server and $\mathrm{P} 2 \mathrm{P}$ network," Automation in Construction, vol. 45, pp. 72-85, 2014.

[19] M. T. Shafiq, J. Matthews, and S. R. Lockley, "Requirements for model server enabled collaborating on building 
information models," International Journal of 3-D Information Modeling, vol. 1, no. 4, pp. 8-17, 2012.

[20] V. Singh, N. Gu, and X. Wang, "A theoretical framework of a BIM-based multi-disciplinary collaboration platform," $A u$ tomation in Construction, vol. 20, no. 2, pp. 134-144, 2011.

[21] U. Isikdag and J. Underwood, "Two design patterns for facilitating Building Information Model-based synchronous collaboration," Automation in Construction, vol. 19, no. 5, pp. 544-553, 2010.

[22] S. Jones, D. Laquidara-Carr, A. Lorenz, B. Buckley, and S. Barnett, "The business value of bim for infrastructure 2017," Smart Market Report, vol. 21, 2017.

[23] M. H. Construction, "The business value of BIM for infrastructure: addressing America's infrastructure challenges with collaboration and technology," Smart Market Report, vol. 12, 2012.

[24] J. C. P. Cheng, Q. Lu, and Y. Deng, "Analytical review and evaluation of civil information modeling," Automation in Construction, vol. 67, pp. 31-47, 2016.

[25] A. Bradley, H. Li, R. Lark, and S. Dunn, "BIM for infrastructure: an overall review and constructor perspective," Automation in Construction, vol. 71, pp. 139-152, 2016.

[26] F. Guo, C. T. Jahren, Y. Turkan, and H. David Jeong, "Civil integrated management: an emerging paradigm for civil infrastructure project delivery and management," Journal of Management in Engineering, vol. 33, no. 2, Article ID 04016044, 2017.

[27] A. Costin, A. Adibfar, H. Hu, and S. S. Chen, "Building Information Modeling (BIM) for transportation infrastructure-literature review, applications, challenges, and recommendations," Automation in Construction, vol. 94, pp. 257-281, 2018.

[28] H. Y. Chong, R. Lopez, J. Wang, X. Wang, and Z. Zhao, "Comparative analysis on the adoption and use of BIM in road infrastructure projects," Journal of Management in Engineering, vol. 32, no. 6, Article ID 05016021, 2016.

[29] S. A. Biancardo, N. Viscione, A. Cerbone, and E. Dessì, "BIMbased design for road infrastructure: a critical focus on modeling guardrails and retaining walls," Infrastructures, vol. 5, no. 7, p. 59, 2020.

[30] S. A. Biancardo, A. Capano, S. G. De Oliveira, and A. Tibaut, "Integration of BIM and procedural modeling tools for road design," Infrastructures, vol. 5, no. 4, p. 37, 2020.

[31] O. Koseoglu, M. Sakin, and Y. Arayici, "Exploring the bim and lean synergies in the istanbul grand airport construction project," Engineering, Construction and Architectural Management, vol. 11, 2018.

[32] S. A. Biancardo, N. Viscione, C. Oreto, R. Veropalumbo, and F. Abbondati, "BIM approach for modeling airports terminal expansion,” Infrastructures, vol. 5, no. 5, p. 41, 2020.

[33] L. Zhao, Z. Liu, and J. Mbachu, "An integrated BIM-GIS method for planning of water distribution system," ISPRS International Journal of Geo-Information, vol. 8, no. 8, p. 331, 2019.

[34] M. Wang, Y. Deng, J. Won, and J. C. P. Cheng, “An integrated underground utility management and decision support based on BIM and GIS," Automation in Construction, vol. 107, Article ID 102931, 2019.

[35] P. Huethwohl, I. Brilakis, A. Borrmann, and R. Sacks, "Integrating RC bridge defect information into BIM models," Journal of Computing in Civil Engineering, vol. 32, 2018.

[36] Q. Wang, H. Sohn, and J. C. Cheng, "Automatic as-built BIM creation of precast concrete bridge deck panels using laser scan data," Journal of Computing in Civil Engineering, vol. 32, no. 3, Article ID 04018011, 2018.
[37] B. Fanning, C. M. Clevenger, M. E. Ozbek, and H. Mahmoud, "Implementing BIM on infrastructure: comparison of two bridge construction projects," Practice Periodical on Structural Design and Construction.vol. 20, no. 4, Article ID 04014044, 2015.

[38] Y. C. Lin, "The study of collaboration-based BIM models development for GCs in Taiwan," The Report for BIM Implementation in Practice, vol. 12, 2017. 